\title{
TENDENCIAS, FRACTURAS Y QUIEBRES EN LA DISCURSIVIDAD POLÍTICO-ELECTORAL COSTARRICENSE. ANÁLISIS POLÍTICO- DISCURSIVO DURANTE EL PROCESO DE LA CAMPAÑA PRESIDENCIAL 2013-2014
}

\author{
TRENDS, FRACTURES AND BREAKS IN THE COSTA RICAN \\ POLITICAL ELECTORAL DISCOURSE. ANALYZING THE POLITICAL \\ DISCOURSE DURING THE PRESIDENTIAL CAMPAIGN 2013-2014
}

\author{
Pablo Carballo Chaves*
}

\begin{abstract}
RESUMEN
Las recientes elecciones presidenciales en Costa Rica (2013-2014) dejaron ver una serie de circunstancias que van desde tendencias históricas, pasando por fracturas hasta quiebres socio-simbólicos que han recompuesto el escenario de los mensajes políticos. Este artículo realiza una introducción al estudio de dicho proceso desde tres dimensiones interrelacionadas: los partidos políticos, los candidatos y los elementos de la cultura política costarricense. Se cierra con una conclusión sobre la tendencia a la personalización como factor básico en la era de los medios de comunicación y la individualización, con una fractura en la disputa por los símbolos políticos legítimos como la centralidad y finalmente, con un quiebre en el sentido de una incorporación reciente en la terminología de uso en los discursos y mensajes electorales que dan un matiz distinto y con diferentes horizontes para el estudio de la comunicación política costarricense.
\end{abstract}

PALABRAS CLAVE: COMUNICACIÓN * POLÍTICA * DISCURSOS * ANÁLISIS * ELECCIONES

ABSTRACT

The recent presidential elections in Costa Rica (2013-2014) left to see a number of circumstances ranging from historical trends, through fractures to socio-symbolic breaks that have recomposed the scene of political messages. This paper makes an introduction to the study of that process from three interrelated dimensions: political parties, candidates and political elements of the Costa Rican culture. The study concludes by analyzing the trend of personalization as a basic factor in the age of media and individualization, a fracturein the dispute over the legitimate political symbols such as centrality, and finally with a break in the sense of a recent addition in terminology used in speeches and electoral messages that gives different horizons for the study of Costa Rican political communication tone.

KEYWORDS: COMUNICATION * POLITICS * SPEECHES * ANALYSIS * ELECTIONS

Universidad de Costa Rica (UCR), Universidad Estatal a Distancia (UNED), Facultad Latinoamericana de Ciencias Sociales, Costa Rica (FLACSO).

carballopablo@gmail.com 


\section{INTRODUCCIÓN: RAZÓN DEL ESTUDIO}

El plano político costarricense está viviendo un fenómeno con dimensiones aparentemente inusuales desde el punto de vista socio-histórico. Las elecciones ocurridas en febrero $y$ después en abril $^{1}$ del 2014, muestran un escenario en tránsito hacia una recomposición de las fuerzas y tendencias socio-electorales y políticas en general. La elección de Luis Guillermo Solís como presidente, una figura "nueva" en varios frentes y su Partido Acción Ciudadana (PAC), relativamente reciente - formado en el 2001 - advierten de distintos temas y problemáticas de estudio. En este artículo, se detalla sobre la combinación analítica de discursos, proceso de comunicación política y comportamiento socio-electoral. Se enfocará en preguntas orientadoras: ¿qué tendencias en discursos existen en la dinámica comunicativa de la política costarricense? y ¿qué discursos se manifiestan en dicho proceso comunicativo como fracturas o en caso novedoso, quiebres?

Al ser una problemática de carácter social, político y nacional es importante indicar que este artículo ${ }^{2}$ se desprendió de un proyecto mayor, que buscó analizar propiamente el proceso de comunicación política del gobierno central de Luis Guillermo Solís en el abordaje de la conflictividad social ${ }^{3}$. Sin embargo, este documento

1 Como lo indica la Constitución Política de Costa Rica (art. 158), si ninguno de los partidos alcanza el $40 \%$ de los votos válidamente emitidos, se realizará obligatoriamente una segunda ronda. En Costa Rica solo se han efectuado segundas rondas en dos elecciones, primero en el 2002 y luego en el 2014. En ambas oportunidades el partido más antiguo, Partido Liberación Nacional (PLN), perdió las elecciones presidenciales.

Una versión previa de estas ideas se presentaron en una ponencia en septiembredel 2014 en el III Congreso en Comunicación Política en Santiago de Compostela, España. Organizado por la Asociación Latinoamericana de Investigadores en Campañas Electorales (ALICE), la cual lleva por título: "Tendencias, fracturas y quiebres de la política costarricense. Análisis del proceso comunicativo en la campaña electoral 2013-2014".

3 El proyecto se titula: "Estudio de la comunicación política del Gobierno Central Costarricense y el abordaje del conflicto social durante el primer año precisa en elementos analíticos discursivos para comprender el porqué Luis Guillermo Solís logra ganar las elecciones con un partido sin previas experiencias como gobierno central.

Las últimas elecciones presidenciales y para diputados en Costa Rica presentaron una carga política y comunicacional que viene a reevaluar los vínculos simbólicos y la forma de valorar la construcción de campañas políticas. La victoria electoral de un candidato "desconocido" —Luis Guillermo Solís- en relación con su partido relativamente "nuevo", marcó una novedad en el plano mediático. Además, en el contexto de un sistema político desacreditado, los diferentes partidos intentaron canalizar la carga de molestia y distanciamiento de la política en un sentido electoral-representativo, es decir, atraer esa carga de molestia y convertirla en votos ${ }^{4}$. Como se verá, dicho volumen electoral se canalizó hacia el PAC por su carga simbólico-discursiva en asociación con el contexto de malestar. Es decir, se dio un viraje y la dinámica partidista histórica enfrentó una revisión de apoyo en relación con la legitimidad de los partidos tradicionales, frente a una visión de novedad $y$ aparente "pureza" política.

\section{ELEMENTOS CONTEXTUALES: COSTA RICA} 1990-2014

Ninguna campaña electoral sucede en un vacío socio-político y para poder

de gobierno de Luis Guillermo Solís: 2014-2015". Está inscrito en la Escuela de Sociología de la Universidad de Costa Rica a efectuarse entre enero $y$ diciembre del 2015. Director formal del proyecto: M.Sc. Pablo Carballo Chaves y coinvestigador Lic. José D. Rodríguez Arrieta.

4 Aún así, el peso del abstencionismo se sigue considerado alto. En las votaciones de febrero, el rubro por abstención fue más alto que cualquiera de los partidos, con un $31 \%$ del padrón electoral (datos del Tribunal Supremo de Elecciones, Costa Rica). Inclusive, en la segunda ronda entre los dos partidos que alcanzaron dicha instancia, los votos validos emitidos para los candidatos fueron: PAC $78 \%$ y PLN 22\%; el abstencionismo para la segunda ronda fue de $43 \%$. Lo anterior indica que dichos $78 \%$ y $22 \%$ son sobre la base de voto efectivo de $57 \%$, siendo casi la mitad del padrón el que no acudió a votar en la segunda ronda. 
comprender dicho escenario se presenta de manera resumida un entorno contextual. Este permite vislumbrar el proceso costarricense en materia política en los últimos 24 años ( 6 gobiernos transcurridos: 3 del Partido Unidad Social Cristiana -pusc-, 3 del Partido Liberación Nacional -PLN-), con el fin de justificar el punto señalado sobremalestar de la población en las acciones políticas de las autoridades y principalmente del gobierno. En el cuadro 1 , se unifica de manera condensada dicha historicidad socio-política.

El manejo del gobierno costarricense giró en torno a una élite política histórica formada durante el siglo xix, la cual para finales del siglo xx se orientó hacia una visión de mercado, apertura comercial y globalización, debido a los programas e iniciativas generales de los partidos tradicionales que accedieron al gobierno. En 10 años (1990-2000) se marcó un uso simbólico tanto paternalista como nostálgico, mostrado en la presencia de los hijos de los caudillos en la presidencia del país (Juan Rafael Calderón Fournier y José María Figueres Olsen), pero que más allá de esa aparente nostalgia se gestionó una lógica de gobierno basada en la integración global a mercados internacionales.

La idea de utilizarse o apelar a los hijos de los caudillos buscó generar la idea de una visión de renacimiento nacional basado en una perspectiva internacionalista, donde el papel del país está en función de su unificación con los mercados internacionales y la apertura políticoeconómica. No pasa desapercibida la similitud en la continuidad de la agenda política, más allá de la diferencia de partidos en el gobierno durante los 24 años de la dupla pusc-pln en el gobierno. Asimismo, se asocia históricamente la dirección del país con un grupo específico que lidera el control del Estado.

Desde el año 2001 y hasta el 2006 se abre un contexto crítico de la población sobre el accionar político formal de los gobiernos de la República, y se evidencia con fuerza un malestar generalizado sobrelos funcionarios públicos en cargos presidenciales y/o públicos en general, así como de los partidos políticos ${ }^{5}$. Esto debido a las acusaciones de varios presidentes de ambos partidos grandes/tradicionales por presuntas faltas de ética y también por favoritismo en procesos de concesiones o compra de equipo. Todo esto generando una insatisfacción y pesadumbre social en torno a los políticos y sobre la visión de la política, asumiéndola como "corrupta" .

En el año 2006, se reelige a Óscar Arias Sánchez (quien había sido presidente en el periodo 1986-1990) por parte del PLN. La forma en la que Óscar Arias accede a ser nuevamente candidato se debió a una interpretación desde la Sala Constitucional de Costa Rica (Sala IV), debido a que había una prohibición sobre la reelección en la Constitución Política.

De esta situación surgen nuevas líneas para el cuestionamiento sobre la visión democrática costarricense y la legitimidad sobre los representantes. Tanto así que en dicha elección $y$ en los resultados del primer referéndum realizado un año después de la elección de Óscar Arias (2007), tienen prácticamente un empate en términos del apoyo electoral (aunque ganaron por el mínimo Arias y la aprobación del Tratado de LibreComercio -TLC-). Asimismo, Laura Chinchilla (pLN) queda presidenta de la República, siendo la primera mujer en ser elegida para dicho puesto. No obstante, a partir de su tercer año de mandato, la credibilidad y percepción socio-mediática alcanza un tono de inoperancia fuertemente marcado.

$5 \quad$ En este punto se acerca a una visión de realineamiento de los partidos políticos. Para una reflexión sobrela diferencia entredesalineamiento $y$ realineamiento político (a nivel de partidos) véase: Carrera, 2012. 


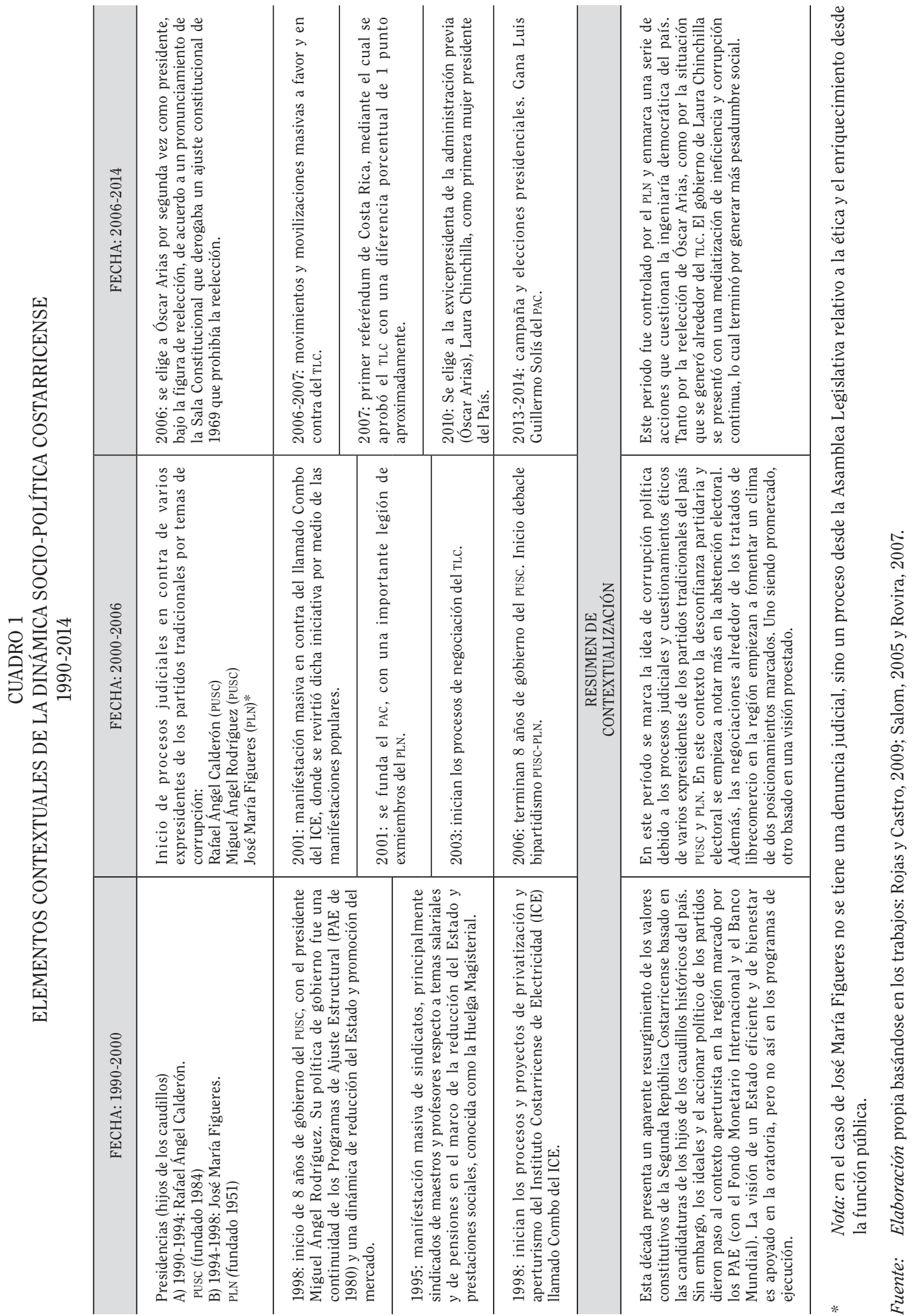




\section{BREVE DESCRIPCIÓN METODOLÓGICA}

Las campañas políticas y principalmente la dinámica política, entroncan una serie de elementos que son amplios y complejos de estudiar. En esta aproximación se hace énfasis en la relación que existió y existe entre los mecanismos de comunicación social masivos en la aproximación respecto a una serie de factores que pesan en el proceso político-electoral.

En el cuadro anterior se muestran los factores (instituciones $y$ actores) que se vivieron en el contexto electoral de la pasada campaña costarricense (2013-2014) para presidente $y$ diputados. En el cuadro 2, se sintetiza un conglomerado de elementos que son clave durante la campaña, organizado en tres dimensiones: A) institución partidaria, B) identificación personal (candidato) y C) contexto político-cultural. Por razones analíticas se concentra en el estudio de la campaña presidencial solamente, porque en ella se visualiza con mayor fuerza la complejidad socio-política del país.

\section{CUADRO 2}

FACTORES, ACTORES Y ELEMENTOS ANALIZADOS EN EL CONTEXTO DE LA CAMPAÑA ELECTORAL COSTA RICA, 2013-2014

\begin{tabular}{lll}
\hline FACTOR INSTITUCIONAL & FACTOR PERSONAL & FACTOR CONTEXTUAL** \\
\hline 1. PLN & 1. Johnny Araya & El "centro" \\
2. PAC & 2. Luis Guillermo Solís & "Izquierda del diablo" \\
3. Otros partidos participantes*: & 3. Otros candidatos: & Otros factores: \\
- Partido Frente Amplio (PFA) & - José María Villalta & -Tipo de votante \\
- Partido Movimiento Libertario (PML) & - Otto Guevara & -Medios de comunicación diverso \\
- PUSC & - Rodolfo Piza & -Giro a la izquierda latinoamericana \\
\hline
\end{tabular}

Nota *: en total, en las elecciones de febrero 2014, participaron 13 partidos políticos. Para valorar los resultados de cada uno se puede acudir al Tribunal Supremo de Elecciones (TSE) de Costa Rica.

Nota **: este factor contextual no sigue una lógica lineal con las casillas de los restantes factores del cuadro. Es decir, no debe leerse como correspondiente a un candidato o partido en específico, sino como el marco que engloba en la dinámica lo político-electoral.

Fuente: Elaboración propia basada en la campaña electoral 2013-2014, Costa Rica.

El abordaje es sobre la discursividad y la comunicación política en los aspectos contextuales. En este sentido es importante evidenciar cuáles medios de comunicación fueron considerados para entender el proceso de comunicación acaecido (cuadro 3). Para efectos tanto comparativos como simbólicos, se hace una distinción con el fin de señalar el tipo de medio de comunicación interviniente: tradicional/digital. Un medio tradicional es aquel que cumple dos requisitos: tiene una tecnología comunicativa no digital (pero además tiene páginas electrónicas) y a su vez, están constituidos en empresas o corporaciones de comunicación.
Un medio digital solo cumple el requisito de tener esa condición técnica comunicativa en Internet. Esto permite valorar las empresas de comunicación tradicionales, pero que tiene formas técnico-comunicacionales digitales, como serían sus páginas de Facebook y Twitter. Asimismo, se dan formas de comunicación explícitamente digitales, como sería periódicos digitales y blogs, que no son tradicionales.

Esta división tiene un carácter descriptivo, es decir, interesa mostrar las fuentes desde donde se articularon los resultados analíticos y no profundizar en las diferencias entre la aproximación comunicacional de las personas que 
acuden a distintos medios. Además, existe un interés en estudiar principalmente la producción discursiva mediante los canales de rango de difusión más amplio y con una perspectiva de legitimidad social, por eso se enfocará en los medios de comunicación tradicionales.

\section{CUADRO 3 \\ MEDIOS DE COMUNICACIÓN ESTUDIADOS DURANTE LA CAMPAÑA ELECTORAL COSTA RICA, 2013-2014}

\begin{tabular}{ll}
\hline MEDIOS DE COMUNICACIÓN: TRADICIONALES & MEDIOS DE COMUNICACIÓN: DIGITALES \\
\hline Televisión (Canales: 6-7-9-13) & Facebook \\
Radio (Columbia y Monumental) & Twitter \\
Prensa (La Nación, La Extra, El Financiero, entre otros) & Páginas digitales, medios tradicionales \\
\hline
\end{tabular}

Fuente: Elaboración propia basada en la campaña electoral 2013-2014, Costa Rica.

Lo fundamental no es mostrar la diferencia, sino más bien la complementariedad comunicacional que existe entre diferentes medios, así como su modalidad técnica y de alcance masivo en la producción discursiva. Es importante aclarar que se seleccionaron fragmentos de la base más grande de material, bajo la organización del cuadro 2 .

A partir de este punto es que se indican los elementos de conocimiento que fueron usados discursivamente en la construcción de la campaña en sus diferentes dimensiones: institucional, personal y de valores culturales. La idea es condensar un marco global de ideas clave para entender las rutinas y los distanciamientos respecto a la discursividad en la pasada elección presidencial.

\section{CRITERIOS TEÓRICOS: COMUNICACIÓN POLÍTICA, CAMPAÑA Y DISCURSO}

La construcción de estrategias de campaña enmarca en primera instancia el clima político y los acontecimientos sociales inmediatos y estructurales de cualquier situación electoral. La comunicación política profundiza en el entramado discursivo y en la utilización técnica de recursos diversos, y no es ajena al contexto socio-histórico.

El escenario costarricense presenta un aglutinamiento bajo la idea reproducida ideológicamente de un consenso histórico, pero que últimamente ha estado marcada por la necesidad de cambio, o al menos una modificación significativa de mejoría. En este sentido, las campañas electorales costarricenses tienen como eje vincular el enfoque sobre esa capacidad de consenso a nivel histórico. Sin embargo, no solo existe el consenso:

Todas las formas de gobernación pueden remitirse a una tipología binaria, sumaria, pero que sirve al objetivo de nuestra reflexión: sociedades que se gobiernan por conflicto, sociedades que se gobiernan por consenso. Las primeras recurren a la fuerza. Las segundas, a la comunicación. Las primeras reprimen, en tanto las segundas aceptan la conflictividad, $y$ buscan la manera de encauzarla $y$ darle soluciones adecuadas (Del Rey Morató, 1989, p.64).

Precisamente, evidenciar estas dos posturas - versión del consenso y versión del conflicto $^{6}$ - fue lo que ocurrió en la campaña

$6 \quad$ ¿Qué tan consistentes y profundos son la visión y el discurso del conflicto?, es un tema que se sale del marco de este artículo, pero que se contempla en alguna medida en el proyecto de investigación general. 
electoral del 2013-2014, lo cual marca una visión de modificación respecto a los patrones reconocidos.

La comunicación política señala un énfasis sobre ese nivel de consenso, que sin dejar de lado la conflictividad, releva las capacidades de transmisiones de ideas, propuestas, $y$ de generación de estratagemas comunicacionales y persuasivas. Así, uno de los ejes analíticos se basa en el nivel discursivo bajo el cual, las propuestas electorales articularon la posibilidad de canalizar el consenso ${ }^{7}$. Esto se valora según la división propuesta por partidos políticos, candidato y elementos de cultura política. Los partidos políticos son la referencia institucional de canalización de intereses sociales, los candidatos son la imagen de la representación partidista, $y$ la cultura política son los valores $y$ acciones que a nivel de identidades se reproducen en las gestiones público-políticas.

Bajo estas ideas, una clave para entender el desarrollo de la campaña de los partidos políticos y candidatos es reconocer, - como se mencionó en la introducción- la generación de un espacio de imagen pública y de dinámica política formal fuertemente cuestionada. El marketing político desmedido ha tenido mucho que ver en esa debacle de credibilidad:

Pero más grave todavía ha sido el hecho de que la inexperiencia de nuestros partidos políticos en temas de publicidad $y$ de marketing electoral los haya conducido a una sobreutilización de los recursos publicitarios más allá de cualquier análisis de rentabilidad, lo cual está en buena medida en el origen de las prácticas de financiación irregular que se han prodigado entre nosotros durante los últimos años,

$7 \quad$ No se está utilizando la teoría que se denomina la "Estrategia de la Crispación" (Maravall, 2009), pero es perfectamente compatible para analizar el fenómeno acontecido durante la campaña electoral 2013-2014. Dicha estrategia analítica se utilizó para reflexionar sobre lo sucedido en la confrontación que existió durante el TLc. Véase: Treminio, 2010. Tampoco es incompatible con una versión de voto hacia el "centro", como se ha propuesto en otras reflexiones (Carballo, 2015) y la propuesta en este artículo. contribuyendo a generar un clima de corrupción generalizada que ha terminado por afectar a la propia credibilidad del sistema democrático en su conjunto (Caro, 1994, p.81-82. Cursivas del autor).

Así, uno de los principales retos que la campaña política tenía que sopesar fue la separación de una considerable masa electoral de los partidos, especialmente los tradicionales y lograr recanalizar el empuje hacia las dinámicas de votación.

Las modificaciones mediáticas han tenido un empuje constante en la producción de mensajes de todo tipo, con un particular énfasis político que articula la distribución y organización desde el poder. Las redes digitales de comunicación (conocidas habitualmente como redes sociales) han marcado una forma mucho más compleja de comunicación política, que ha mermado y criticado la verticalidad de las formas de comunicación unidireccional clásicas desde los modelos de Harold Lasswell y su aguja hipodérmica, pasando por Paul Lazarsfeld y sus ejes protagonistas de los "líderes de opinión", entre otros modelos que tuvieron un impacto mediático en las sociedades globales. Sin embargo, de la tradición funcional-clásica se rescata que:

Utilizando una sofisticada metodología de encuestas en panel (una amplia muestra de personas entrevistadas en varias ocasiones previas a la fecha de elección), Lazarsfeld encontró que los medios masivos de comunicación no tenían una influencia decisiva en los votantes, sino que estos eran persuadidos mayormente por miembros de sus grupos primarios 0 de referencia a los que consideraban líderes de opinión (Lozano, 1997, p.48).

Como se desprende de esta cita, la credibilidad y el prestigio de las opiniones influye en las campañas políticas y en las elecciones presidenciales costarricenses del 2013-2014. El marco de opiniones negativas principalmente apuntaron hacia el candidato $y$ partido oficialista, creando una campaña global "antipls". De esto se puede interpretar que existió un marco para que cualquier otro partido pudiera aprovechar 
el contexto de repudio ${ }^{8}, y$ fue donde un grupo de líderes de opinión establecieron una agenda temática permisiva con el objetivo de cuestionar al gobierno y al candidato del pLn, con una virulenta campaña desde diferentes flancos. Sin embargo, para tomar ventaja, los partidos ${ }^{9} y$ principalmente, la imagen de candidato, tenían que desarrollar ciertos rasgos culturales asociados a una identificación social en la historicidad política costarricense.

Dos de los fundamentos de dicha historicidad política, que redunda en la forma cultural de vivir y ejercer la política en el país son: la visión de una mítica centralidad —justo medio-y la atención en los debates político-electorales, en los cuales la disputa política tuvo una importante forma de canalización, que no se había dado en los últimos años (Carballo, 2015). La idea de considerar el centro o votar por el centro, está asociada a una idealidad de armonía política, que se une a la ideología de "paz" con que la institucionalidad social costarricense se ha construido durante varias décadas. La idea del "centro" como poder aglutinador y legitimador del poder es abierto a lógicas y culturas humanas diversas (Eliade, 2013). Pero en el caso costarricense, el factor de votar lo más cerca del centro combina la idea de lo justo, hace alusión a la igualdad mítica y a la idea de que el cambio (que fue eslogan generalizado de campaña) tiene que buscar un momento de neutralidad ideológica, que demuestre una cuasi idealidad social. Además de proporcionar un cálculo de credibilidad en la elaboración de campaña desde lo que se podría llamar la "colonización del centro" (Carballo, 2015).

$8 \quad$ El problema de repudio no es solamente ante un único partido, sino generalizado hacia el dinamismo de los partidos políticos, así como a la credibilidad sobre las elecciones y la política, lo cual se ha visto reflejado en el abstencionismo (Rojas y Castro, 2009; Raventós, Fournier, Ramírez, Gutiérrez y García, 2005).

9 Aunque los partidos unifican en gran medida el accionar político electoral, en Costa Rica la credibilidad de estos ha decaído desde hace más de 15 años (Rojas y Castro, 2009 y Rodríguez, 2013).
El partido que canaliza una posición de "centro" fue el PAc, ya que logró ocupar dicha centralidad gracias a la existencia de partidos que mostraban "extremos" o cuotas de nocentralidad. Como se puede observar, el votante costarricense, pese a poder estimular y divulgar una idea de cambio, este está condicionado en alguna medida, a un punto de "aparente seguridad". Esta connotación de cambio está matizada, no por una cuestión de variación radical, sino más bien hacia una "estabilidad idílica", aprovechada estratégicamente desde diferentes frentes partidistas $y$ desde los candidatos.

Las nuevas tecnologías en general, y en especial las tecnologías de la información, han reconstruido procesos sociales y políticos con una actualización en términos de acceso y construcción del conocimiento. Así también, han contribuido en la visibilización de personas, grupos y fuerzas sociales que hasta hace recientes períodos eran sobrepasados por controles socio-políticos mucho más estrictos en términos de difusión de ideas y propuestas.

Estos cambios han hecho que las dinámicas electorales y políticas se vieran en una situación de inercia social no tan clara de valorar en algunos aspectos, pero que han mostrado una tendencia a generar patrones de críticas mucho más amplias de lo que las formas de comunicación de masas tradicionales (televisión, radio y prensa) suelen tener. La organización se ha visto también alterada y repensada en términos de transmisión de ideas y propaganda; la idea de producción mediática ha estado cargada con un doble consumo: 1) un consumo tradicional/ monológico y 2) un consumo plural. Ambos consumos presentan patrones de control de la información distintos; el primero cerrado y controlado desde centros (medios de comunicación de masas clásicos) y el segundo un espacio de construcción y consumo de un rango mayor de opciones y opiniones diversas, con tendencia a la contradicción. Pero pese a exhibir consumos distintos, también se entrecruzan; este punto es el que en este documento se le da prioridad analítica, ya que el entrecruzamiento permite la evolución de las ideas y los discursos, renovando ideales, reconstruyendo pasados y de manera fundamental, reelaborando los códigos 
de lenguaje que son básicos en la comunicación política.

Este tipo de abordajes desde la comunicación y los lenguajes no están fuera del marco de los liderazgos y de los códigos tradicionales de la política electoral y de partidos. Sin embargo, los patrones de comunicación, debido a la dimensión virtual de Internet, han criticado la visión "teledemocrática" que se tenía de la política, donde:

En resumen, el espectáculo político es posible gracias a la hibernación de la ciudadanía pasiva, la cual, puede decirse, es activada desde un extrañamiento. Así pues, se considera que en las teledemocracias se han establecido un nexo singular entre los símbolos y rituales, por un lado, y la apatía de los ciudadanos, por el otro: la apatía se considera el resultado tanto de las características de la competencia política, o sea de sus contenidos, como de la naturaleza del locus en el cual, por lo general, se desarrolla es competencia (el ámbito de los medios de comunicación de masas) (Fabbrini, 2009, p.57).

Las nuevas dimensiones comunicacionales y de producción de comunicación han hecho que los formatos clásicos de direccionalidad y monopolio mediático se cuestionen en la práctica política y se repiensen. Aunque todavía no se está del todo lejos de este modelo y sus alcances, las capacidades de enunciar masivamente se han diversificado, dejando ver el impacto de las telecomunicaciones y la vida digital en los entornos de comunicación y de la política.

El impacto de las interacciones virtuales ha dado una dimensión de asociatividad y ha creado una posibilidad de ciberactivismo que han dado un impulso en la contienda política ${ }^{10}$.

10 Como se señaló en la metodología, el interés de este escrito no es profundizar en ese matiz del impacto de las nuevas tecnologías de la comunicación en la vida política y electoral, pero tampoco se puede olvidar que esta dinámica socio-técnica ha modificado los patrones de consumo y producción discursiva, particularmente para los fines de este estudio, en las contiendas electorales.
La versión de la "sociedad red" (Castells, 1999) ha impulsado una relativa renovación del desempeño político, que no sin ciertos resguardos $y$ dudas, ha posicionado una palestra pública más compleja y donde el conflicto pareciera mostrarse con mayor énfasis.

La capacidad de generar respuestas rápidas $y$ de crear productos informativos y propagandísticos con agilidad de fácil y barata distribución, contribuyó en el posicionamiento frente a grupos de élite que históricamente han tenido una relación estrecha con los medios de comunicación en Costa Rica (Carballo, 2013) a nivel histórico y global. Es importante aclarar que una cosa es el desempeño político $y$ de campaña, $y$ otra la coherencia de partido, logrando la presidencia. En este sentido, la perspectiva teórica prima sobre la estrategia y las reflexiones en la comunicación en tiempo electoral, dejando la coherencia discursiva en la etapa de gobierno para otros análisis.

En términos generales, la reflexión gira en torno a establecer una introducción desde la evolución discursiva durante la campaña electoral desde la enunciación comunicativa de los elementos sociales participantes (actores, instituciones y elementos socio-culturales). Se entiende por discurso una construcción basada en jerarquías de poder y códigos de persuasión y que en términos de análisis se concreta en: “a) la relación existente entre el lenguaje y la sociedad, $y$ b) la relación existente entre el propio análisis y las prácticas analizadas" (Fairclough y Wodak, 2000, p.367). Precisando en su conexión contextual, donde el "discurso debería estudiarse como parte constitutiva de sus contextos local y global, social y cultural" (van Dijk, 2003, p.59). Por lo tanto, se propone analizar los elementos indicados, a partir de los contextos y darle sentido discursivo al fenómeno electoral del 2013-2014, desde la enunciación de las vías comunicativas del mass media.

\section{ANÁLISIS DE LOS FACTORES: PARTIDOS, ACTORES Y VALORES POLÍTICO-CULTURALES}

Como se anunció en la metodología, se analiza el factor de comunicación política desde tres ejes: institucional, personal y contextual. Sin embargo, es importante señalar que el elemento 
contextual está presente en los dos primeros, para darles sentido. El factor cultural y sociohistórico es lo que se refiere como contextual, $y$ aunque se puede $y$ se debe relacionar con los otros, tendrán aquí una breve condensación como códigos de comunicación y acción política en el período electoral estudiado. Se toma con mayor profundidad a los PLN $y$ PAC porque pasaron a la segunda ronda en las elecciones, $y$ se aglutinan en una única categoría al restante número de partidos por una decisión de espacio $y$ pertinencia argumentativa.

\section{LA TRADICIÓN INSTITUCIONAL PARTIDISTA: COMUNICACIÓN Y PARTIDOS POLÍTICOS}

Costa Rica hasta inicios del siglo xxi había mostrado una importancia en la asignación o ubicación partidista, y esta dinámica se convirtió en un modelo bipartidista explícito desde 1986. Sin embargo, después de menos de 20 años, dicho modelo bipartidista se resquebrajó. Fue en el 2014, la primera vez que en más de 60 años de lucha electoral un partido distinto al PLN, Pusc o una coalición (alguna bajo una égida de tendencia calderonista ${ }^{11}$ ), ganan las elecciones presidenciales. Se refiere a una reconstrucción multipartidista del espectro político, sin embargo es prematuro señalar que ya estaría en operatividad ese modelo y todavía se podría indicar una existencia bipartidista si se apela a la ubicación bajo el espectro de derechas e izquierdas. En este sentido:

11 El "calderonismo" es una forma de llamar a personas, grupos o partidos políticos con tendencia social-cristiana, y que durante los años sesenta $y$ setenta formaron alianzas relativas. Surgió a partir del liderazgo del expresidente de Costa Rica Rafael Calderón Guardia -1941-1944- miembro del hoy desaparecido Partido Republicano Nacional. Parte de las alianzas que mostró dicho calderonismo dio paso a la creación entre 1983 y 1984 del partido (y segunda fuerza electoral) Pusc (Molina y Palmer, 2012). ...el hecho del bipartidismo descansa en gran medida en la suposición, por parte de los tratadistas mayoritarios, de que exista una única variable significativa en el sistema político, que es el espectro izquierda-derecha. Los dos partidos pueden entonces ofrecer al electorado moderadas alternativas de derecha $y$ de izquierda. Cuando exista a la vez una dimensión izquierda derecha y, por ejemplo, una dimensión de política exterior favorable a la alienación frente a otra pro neutralidad, $y$ si estas variables no coinciden, los dos partidos serán incapaces de presentar al electorado las cuatro alternativas: pro alienación e izquierdas, pro neutralidad e izquierdas, pro alienación $y$ derechas, $y$ pro neutralidad $y$ derechas (Lijphart, 1999, p.129).

Esta idea debe ser ponderada bajo la luz de que Costa Rica ha presentado una discursividad de centro/neutralidad, aunque de utilizar el espectro de Lijphart, las acciones discursivas costarricenses han sido "pro neutralidad y derechas". Principalmente se ha visto en sus gobiernos y tendencias económicas desde de los años 80. Prueba de eso son los Programas de Ajuste Estructural (PAE: I, II $y$ III) iniciados en administraciones del pun y continuados por el pusc.

Además, el "anticomunismo" ha marcado buena parte de la discursividad política de ambos partidos mayoritarios, que si bien no se fracturó del todo, sí fue puesta en entre dicho debido a lo que Lijphart llama la política exterior (en nuestro caso sería el giro de izquierda latinoamericano), donde la izquierda recobró una presencia en la opinión política costarricense, la cual históricamente se había distanciado. El cuadro 4 condensa los partidos políticos según los elementos socio-históricos relevantes que participan del universo comunicacional de la campaña. 
Tendencias, fracturas y quiebres en la discursividad politico-electoral...

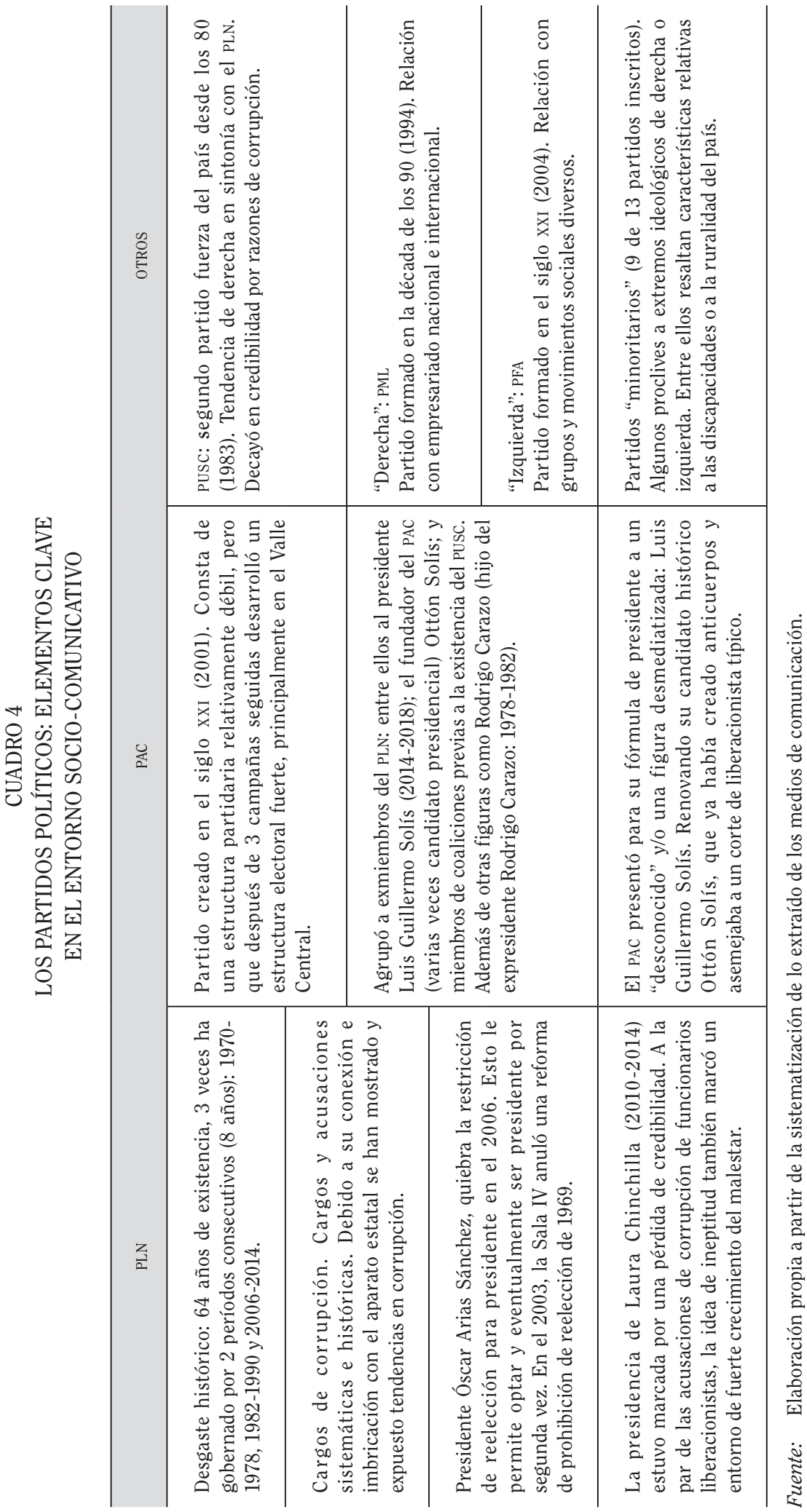




\section{ANÁLISIS DE LOS FLUJOS DE MENSAJE Y COMUNICACIÓN DESDE LA INSTITUCIONALIDAD}

De estos elementos se puede señalar que el PLn ha jugado con el símbolo doble de la experiencia y de la conformación de la Segunda República, principalmente asociado con su figura clave y fundadora José Figueres Ferrer. La construcción del partido oficialista se hizo apelando a esa dimensión rutinaria en sus campañas electorales, aunando en el énfasis en volver a "las vetas" históricas del país (que eran equiparadas e igualadas con las del Partido). El mensaje del pln presentó dos desaciertos, unido a una macrobarrera.

Un primer desacierto fue repetir la fórmula de campaña histórica. Pese a que se hablaba de ser distantes de un "PLn incorrecto", la fórmula de desarrollo de mensajes en campaña fue la misma. Esto no evidenció dicha separación o distanciamiento en ciertos rubros estéticos, inclusive trató de apelar a la idea de familia como elemento discursivo asociado a lo nacional costarricense. El segundo desacierto fue romper con una lógica de "campaña positiva" por una de "campaña negativa" (Ansolabehere y Iyenger, 1995) (esto se vincula con la participación del candidato respecto al factor "guión"12). La "campaña negativa" es atacar a los contrincantes, lo cual no funcionó en el caso del pun, ya que se revela la macrobarrera, que consiste en un espacio o contexto generalizado adverso para el PLN.

Fue tan adverso el contexto que en ambas elecciones (primera y segunda ronda ${ }^{13}$ ), el PLN perdió frente al PAc, $y$ en la segunda ronda el gane del pac fue abrumador, mostrando la peor versión del pln. Además después de la segunda ronda, quedó en un abismo respecto a la deuda política que marcó un escenario negativo

12 Para ejemplos de supuestas "campañas positivas" analícese: José María Figueres Olsen (campaña 1993-1994), Óscar Arias Sánchez (campaña 20052006) y Laura Chinchilla Miranda (2009-2010). Véase: Rodríguez, 2013.

13 En la primera ronda el PAC ganó 31\% a 29\% del PLN. En la segunda fue de $78 \%$ a $22 \%$ (del porcentaje de votos válidamente emitidos). Datos del Tribunal Supremo de Elecciones de Costa Rica. respecto a las capacidades del partido para controlar fondos y no verse como despilfarro de los recursos. En el cuadro 5 se adjunta de manera seleccionada información mediática respecto a lo interpretado.

La fórmula del PAc en términos comunicativos estuvo en jugar la versión de "centro" con mayor consistencia. Esto también estaba conectado con una combinación de "partido relativamente nuevo", pero con gente de experiencia. Estas dos ideas marcaron la producción $y$ oferta comunicativo-discursiva, sumado al recurrente uso de parodias que habían marcado ciertas tónicas electorales previas.

Sin embargo, la exposición de estas ideas no se hizo con una gran cantidad de anuncios, como lo hizo el pLn siguiendo su tradicional dinámica de marketing político. La campaña del pac — también del PFa y otros partidos considerados minoritarios - fue mucho más austera en cierto sentido. Esto, a la larga, caló mejor en un entorno social, donde el despilfarro y la incredulidad a la política y el dinero estaba en su momento más alto.

El pac realizó una posición mediática moderada, pero potenciada a su vez por la deslegitimidad del pln y también del PML ${ }^{14}$. De esto se rescata la idea de que el pac se desenvolvió comunicativamente prudente $y$ a su vez, el clima de "anti pls" o "anticontinuidad", hacen que se valore a los candidatos que tuvieran grados de credibilidad y que también a la larga fueran "políticos despolitizados". La lectura desde la construcción de la campaña respondió en buena medida a este espectro social. Como se analizará posteriormente, el candidato del PAC se presentó como este "político despolitizado". Pero la inicial desmediatización del candidato pasó a una sobremediatización y el pac canalizó mucho en él.

Se dio también una posible visión de cambio, posibilidad de relevo y resolución de pugnas, que el pln no parecía ofrecer. Como institución, el pac (y el esfuerzo del candidato) necesitó mover una masa para asegurar principalmente

14 Esta fue una de las peores campañas para el PML en término de resultados, perdieron 5 escaños legislativos, siendo alrededor del $50 \%$ de sus diputados que pierden respecto al periodo 2010-2014. 
la primera ronda. La segunda ronda fue un espacio para "destruir" al PLN en ese momento electoral. Al pac como al PFA los unía en buena medida una herencia de las vinculaciones creadas durante el TLC $y$ en asociación con grupos o movimientos sociales, lo que hacía que compartierán la mayoría de denuncias, como foco de construcción discursiva (cuadro 1).

El Pfa fue un importante jugador político. En términos proporcionales, el de mayor crecimiento legislativo, pasando de un diputado a 9 $y$ quedando su candidato presidencial en el tercer puesto. Esto para un partido señalado como de izquierda es un gran logro, donde su austera campaña, menos mediatizada, pero más difundida por medios alternativos, tuvo un importante efecto. Este resultado podría relacionarse por ser el partido más combativo, elemento que se debe en una buena medida a su candidato.
En términos del partido, para lograr lo que consiguió, requirió de un desarrollo de estructura amplio, con "muchos frentes", como ellos mismos señalaron. Tanto así que ganaron, en zonas rurales, lo que evidencia donde está su fuerza de base. Por otro lado, su partido antónimo en el espectro histórico-ideológico, el PML, tanto por acusaciones, sospechas de corrupción y asociado con élites político-económicas, fue relevado del peso político que había construido en las dos últimas campañas. Este partido seguía la lógica de mediatización extrema, unificando mensajes populares $y$ de un posicionamiento de "economicismo". El pusc no tuvo mayor resonancia en las elecciones presidenciales, ya que tenía muchos elementos en su contra: denuncias, pugnas internas, entre otros (cuadro 5). 


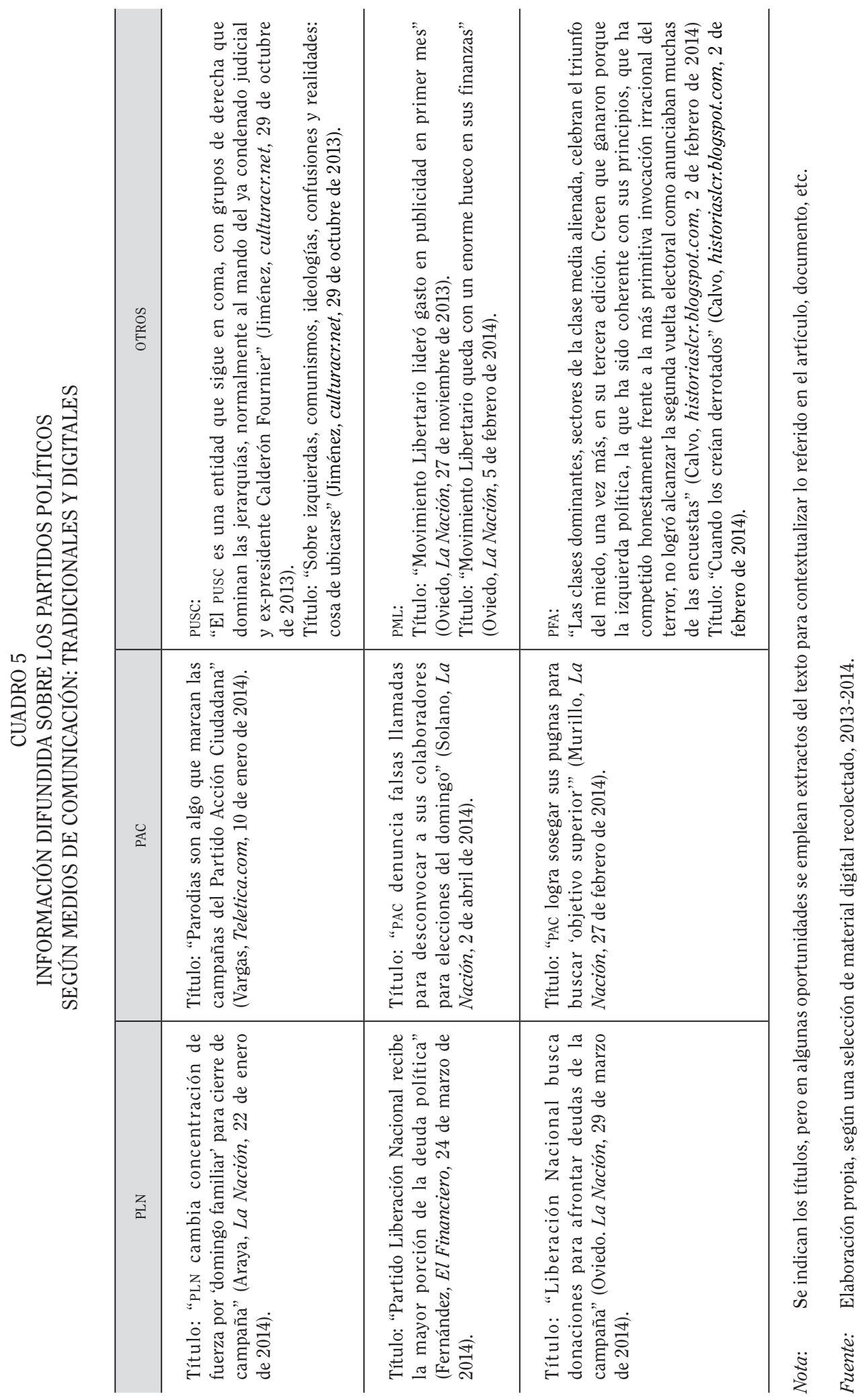




\section{COMUNICACIÓN Y CANDIDATOS PRESIDENCIALES}

La construcción de campañas electorales tiene en un personaje - un candidato- una labor fundamental. No solo se habla de la escogencia de una persona, sino la construcción de una imagen y un símbolo, o símbolos con los cuales identificar dicho candidato. Entre los múltiples elementos con que llenar su papel, el factor del liderazgo es condición sine qua non en el personaje a postular $y$ en este sentido, la personalización es parte de la industria de candidatos, cuando estos pasan por filtros mediáticos.
No es que la personalización a la larga no existiera en etapas premediáticas, ese no es tema de esta discusión, sino que no se puede desvincular analíticamente el filtro que realizan los mass media en la reproducción y participación en la personalización de la figura del candidato. Sergio Fabbrini recuerda que "por lo general (Schudson 1983), la forma estilizada en la que se presenta la noticia política incluye tres características básicas: la dramatización, la simplificación y la personalización de acontecimiento transmitido" (2009, p.59). En el cuadro 6 se señala algunos de los elementos socio-biográficos para la personalización del candidato. 


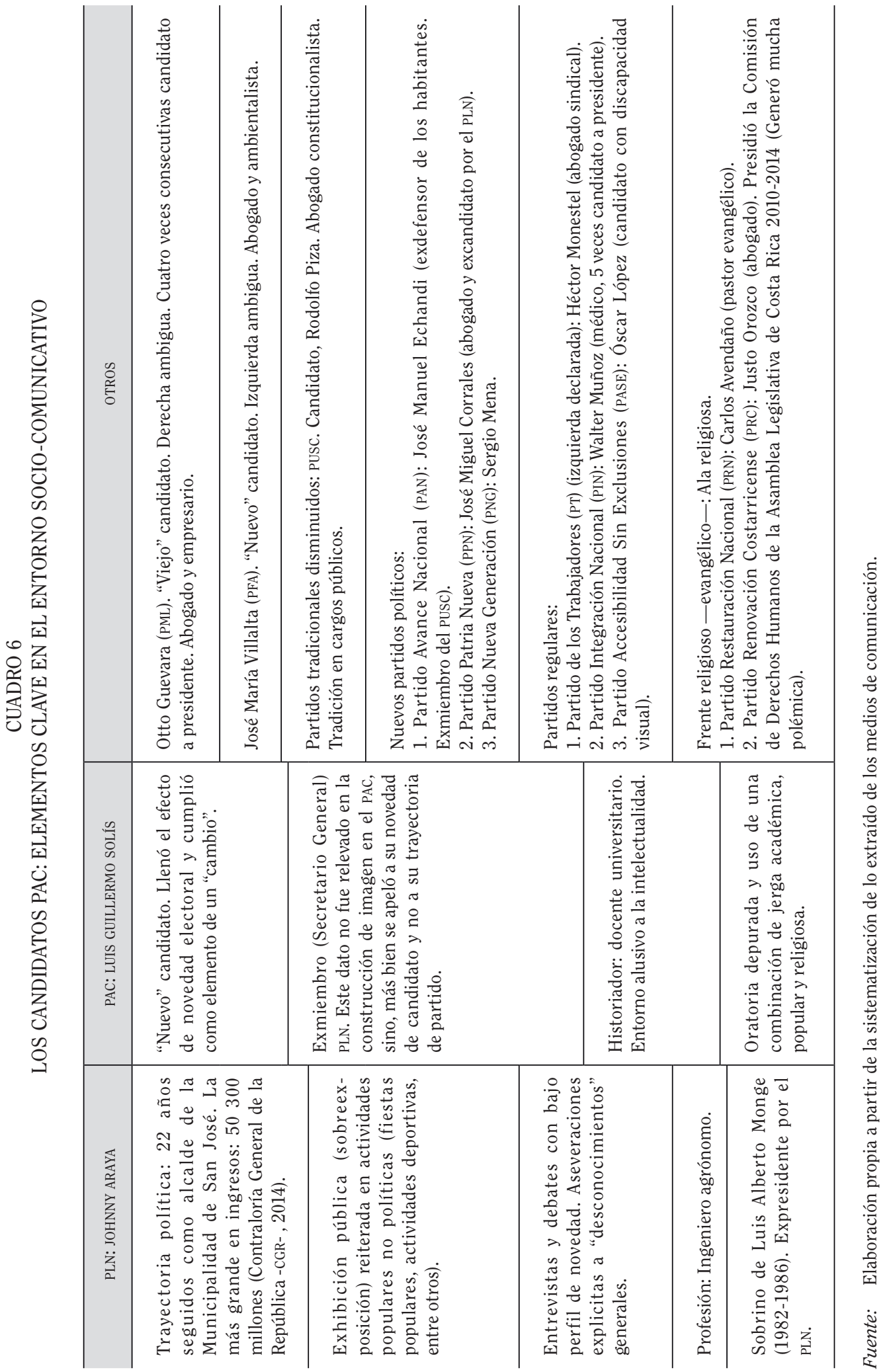




\section{ANÁLISIS DE LOS FLUJOS DE MENSAJE DESDE LA PERSONALIZACIÓN DE LOS CANDIDATOS.}

Aunque la diversidad de candidatos (13 partidos y candidatos) pareciera mostrar una pluralidad ideológica, la constitución en términos de novedad de una personalidad hay que valorarla en dos rubros. La idea de "nuevo", se puede entender de dos maneras: ser una nueva figura en la dinámica política o la segunda, que el personaje sea candidato presidencial por primera vez. De acuerdo al segundo valor de lo "nuevo", de los 13 candidatos, Johnny Araya ${ }^{15}$, Luis Guillermo Solís, José María Villalta, Rodolfo Piza, Sergio Mena y Carlos Avendaño eran candidatos "nuevos".

En este sentido, seis candidatos eran "nuevos" y los restantes 7 candidatos ya habían tenido previamente presencia electoral. Bajo el criterio de novedad y de cómo este elemento juega en la simbolización de un cambio necesario, se puede descartar el peso de aquellos que ya hayan figurado como candidatos, es decir, un punto que juega en contra de la comunicación política es el ser figura rutinaria o conocida en el aura de las campañas electorales. Aunque este factor de novedad no es determinista, sî formó parte del espectro contraproducente para la formulación de estrategias de campaña. Así, la idea de personalidad "nueva" estuvo principalmente del lado de Luis Guillermo Solís y José María Villalta en resultados de pesos electorales. En el cuadro 7 se adjunta de manera seleccionada información mediática respecto a lo interpretado.

15 Johnny Araya fue parte de las elecciones internas en las anteriores comisiones del PLN. Las elecciones internas las perdió contra Laura Chinchilla quien a la larga terminaría siendo la presidenta de Costa Rica por el período 2010-2014. 


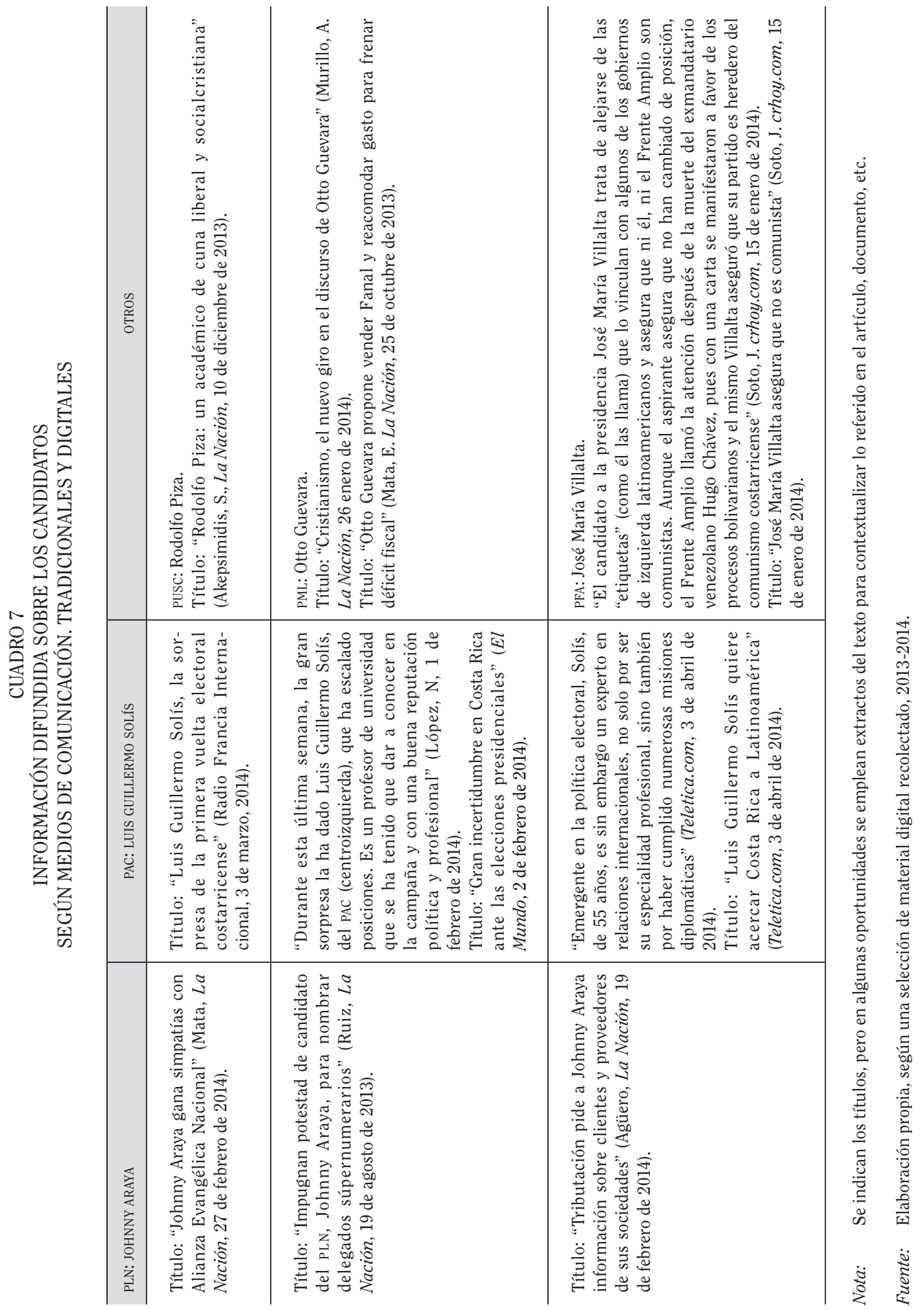


Adicionalmente con la novedad en la construcción de la personalización del candidato, es importante señalar otro elemento: el alejamiento de lo político. Es decir, la construcción de un candidato político "despolitizado" fue un elemento en la construcción de un personaje en alguna medida "puro", esto fue clave en la campaña que el PAC hizo sobre Luis Guillermo Solís, su candidato. A partir de este sentido de novedad, se da el contraste con aquel candidato con vinculación política (con intenciones electorales rutinarias o recientes), el cual se catalogaba como sospechoso de politiquería. Este factor pesó principalmente sobre la campaña y en el candidato Johnny Araya, quien representaba el oficialismo y era un personaje político "fácilmente" cuestionable en el contexto costarricense.

De este modo, se facilitó que Araya se convirtiera en el punto de controversia y enemistad de la sociedad. Asimismo, siguiendo el argumento de Giovanni Sartori (2013), resulta contraproducente en la visión de la claridad analítica, donde en el caso de los medios (particularmente la televisión) reconstruye el evento en términos de ataque como espectáculo:

Se podría pensar que esto sucede porque un ataque puede resultar un espectáculo, y la televisión es espectáculo. En parte, esto debe ser así. Pero el mundo real no es espectáculo y el que lo convierte en eso deforma los problemas y nos desinforma sobre la realidad; peor no podría ser (p. 103).

En otras palabras, la personalización no es un recurso exclusivo de las estrategias de campaña sobre sus propios candidatos, sino un recurso de ataque para presentar al contrincante o contrincantes (tabla 2).

Pese a existir varios elementos a considerar en la construcción de los personajes (candidatos), se sugiere como punto fundamental del análisis la vinculación novedad-pureza, como factor asociado a su individualidad; que en la configuración de sentido da una idea de que la política es un acto de "buenas" o "malas" intenciones, $y$ no de relaciones de poder, lo cual no permite entender claramente el escenario de problemas estructurales y comunicacionales.
Los candidatos de los otros partidos, como fue el caso de Rodolfo Piza, se ubicaron en una visión de debilidad del partido, o por una ambigüedad en el discurso un mensaje no claro, o demasiado abierto como lo fue el caso del Movimiento Libertario (cuadro 7). Quedaría por incorporar a esta reflexión los temas tratados en la campaña, pero eso sale de los márgenes de este artículo

\section{CONTEXTO SOCIO-COMUNICATIVO Y CULTURAL}

La comunicación se enmarca en dimensiones particulares y la dimensión cultural tiene un peso fundamental en el sentido que advierte de las costumbres, dinámicas, orientaciones ideológicas y prácticas diversas que realizan las personas y que tienen impacto en el accionar político-electoral de sus miembros. Sin desarrollar extensamente este punto, se rescatan varios factores de esa complejidad cultural nacionalista costarricense que tiene como principales elementos asociados a la culturapolítica: la mitificación del "centro" y la "demonización" de la izquierda (entre otros posibles). Además, existen otros factores que alteran las dinámicas electorales, que son parte de procesos demográficos y técnico-comunicacionales.

En este sentido, la comunicación de los partidos políticos en conexión con sus personajes/candidatos se desenvuelve en un marco cultural que se presenta en el cuadro 8. Es decir, la estrategia de comunicación y discurso pasó por reconocer estos elementos "flotantes" en la ideologización colectiva y fijarlos en la producción mediática-electoral. Si bien, el cuadro no cubre la complejidad de la cultura política costarricense, permite observar varios puntos medulares que fueron usados en la gran mayoría de los partidos políticos mostrando una tendencia en términos de no cuestionar el modus cultural, sino aprovecharlo en términos de ventaja competitiva (o para no tener déficit cultural) en las elecciones. Aunque algunos partidos trataron de ir contra esta cultura en ciertos puntos; no obstante, no tuvieron igual impacto en términos de efervescencia en el apoyo. Esto debido a las ambiguas y desinformadas ideas que integran lo que se considera la "opinión pública" (Sartori, 2013), con filtros contemporáneos como la televisión y las redes digitales. 


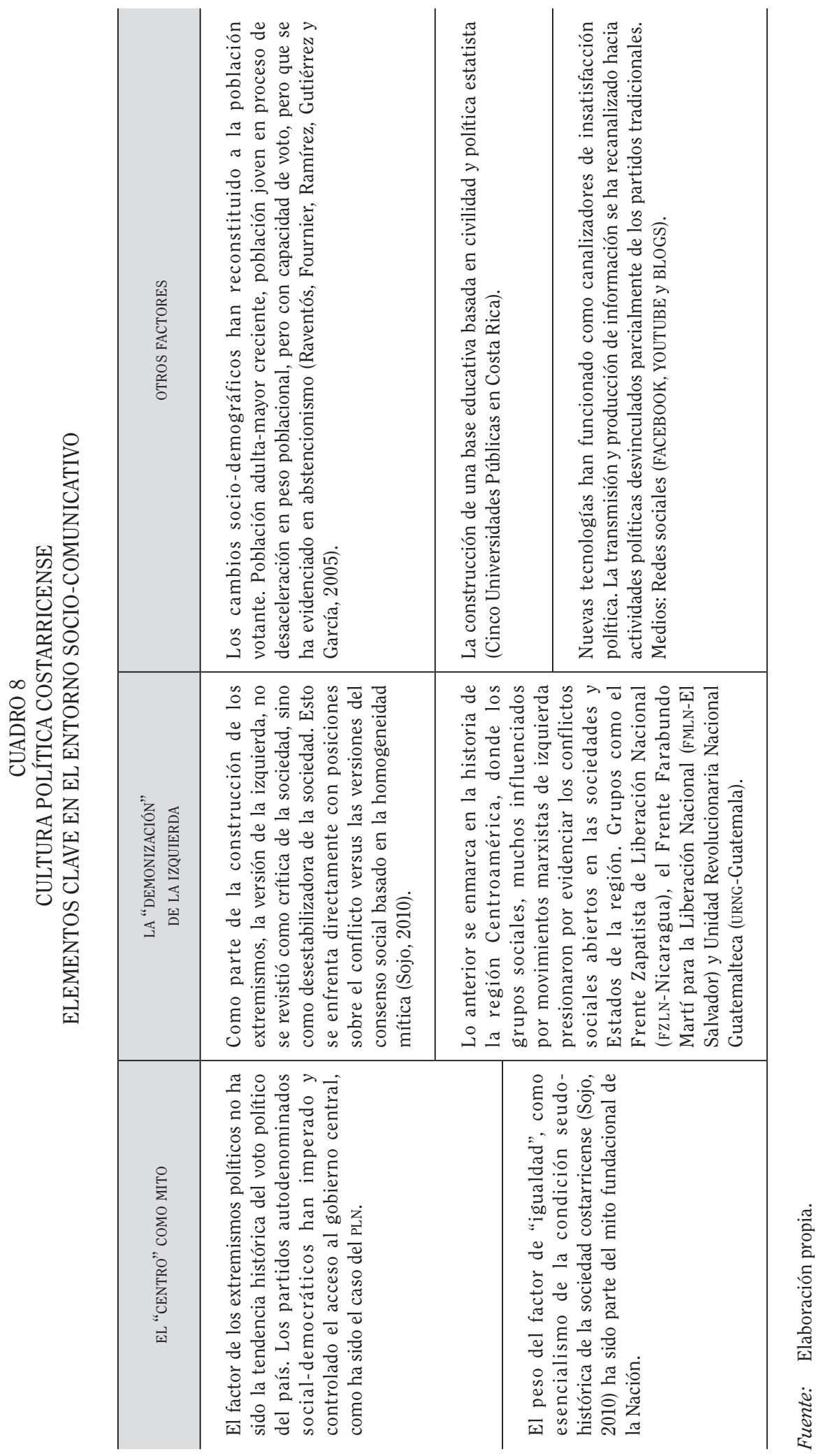




\section{CONCLUSIONES}

Este documento propone una reflexión introductoria en el estudio de la comunicación política durante las elecciones costarricenses para el 2014; es decir, se realiza un análisis inicial buscando canalizar o detectar vetas de cambio social en el plano de los procesos electorales $y$ discursivos en Costa Rica. Pretende ser una primera lectura que oriente perfiles de análisis donde la diversidad temática y teórica se irá exponiendo con el material empírico recopilado (y por recopilar). De lo anterior, las conclusiones se dividen en tres: 1) se evidencia un sentido de tendencia, 2) el quiebre muestra alteraciones en las líneas tradicionales y 3) una fractura, la cual expone modificaciones relevantes que enfatizan en las disonancias discursivas.

\section{TENDENCIA}

La principal tendencia se resume a su vez en tres puntos, donde el factor de la construcción de una personalidad es fundamental en la composición de la campaña. Estos personajes/personalidades se vieron enfrentados por símbolos básicos de la culturalidad política costarricense, la cual es la idea de centralidad ("neutralidad"), revestida de la mítica socialdemocracia desde la década de los 40. Esta tendencia está fundada en la estructuralidad de una sociedad que tiene sus mitos fundacionales atravesados por ideas de "igualdad" y "estatalismo". Por tanto, la comunicación y las estrategias persisten en acercarse sigilosa o ferozmente sobre esos símbolos. Un último punto importante es que fue precisamente el candidato más "nuevo" el que cumplió mejor con ese aparente perfil de "centralidad", con lo cual se observa el valor de lo tradicional en la dinámica política, pero a su vez también en el factor de cambio, que es precisamente donde las fracturas son las evidencias.

\section{FRACTURA}

Se entiende una fractura como una fisura; es decir, una lesión (más no una separación) de la tendencia medular histórica. Así, la fractura de la que se habla sigue la idea continuando con la línea de la tendencia de que la centralidad de la práctica en la cultura política no se dejó de lado, pero si fue repoblada. En este sentido, fue el pac junto a su candidato Luis Guillermo Solís (quien ganó las elecciones en ambas rondas electorales), quienes lograron apropiarse de la idea simbólica y recondicionar las elecciones en términos de opciones "seguras" e "inseguras".

El candidato Solís combinó las idea de cambio de "personajes políticos" con la recuperación de la tradicionalidad ejemplar del país. La fractura se da en términos de actores e instituciones en juego que ya tienen caudal social-simbólico para luchar por símbolos jerarquizados más arriba en el plano nacional. En este sentido, continuando con una idea desarrollada en un artículo previo en una línea similar, donde se llama a esta disputa discursiva y simbólica la "colonización del centro" (Carba1lo, 2015), que fue uno de los marcos de análisis que expresó la contienda comunicativa. El Pac, por medio de su candidato "nuevo" (Solís), se posicionó como un centro "real" o en su defecto el "nuevo centro".

Esto se combina con un desmarcamiento de la tradición partidista en proceso de fractura más sostenida en los últimos 10 años. Esta fractura muestra la delgada línea entre lo "tradicional" y lo "nuevo", dejando ver la evolución discursiva a partir de una lectura del contexto político, aprovechable para nuevas figuras, pero apelando a viejos valores. Incluso, se podría llamar ambiguas (poco claras y en algún sentido incoherente) a las "derechas" y las "izquierdas" en este contexto político, ya que sin entrar a analizarlas a fondo, estas versiones se renovaron en varias oportunidades con valores de "centro", lo cual deja ver la importancia de no perder de vista la relación viejo/nuevo.

\section{QUIEBRE}

Con quiebre se hace referencia a una separación o en este caso, de algo nuevo que ha entrado a formar parte de la discursividad más generalizada de la producción de mensajes. Se habla de "desigualdad social" y la "exclusión social" (no necesariamente profundizados, sino más bien como parte de un refinamiento en el 
lenguaje ${ }^{16}$ ), introducidos por los partidos más nuevos y con una base de izquierda $-y$ que en los últimos años adquirió más uso discursivo en la palestra política-, lo cual tuvo que ser asimilado por partidos tradicionales. Además, dichas nociones han tenido uso en las elocuciones políticas de las últimas campañas, pero tuvieron mayor impacto mediático y discursivo en la reciente campaña.

Si bien, como concepto explicativo las ideas de desigualdad y exclusión son fuertes $y$ de una renovada explicación metodológica ${ }^{17}$, el interés en este artículo está en considerarlos como parte de la nueva cosmovisión lingüística y de comunicación política de las campañas, así como en la producción de sentido del actual gobierno del pac. En otras palabras, el lenguaje político se amplió con nueva terminología, que fue incrustada por la presión de grupos subalternos. Asimismo debido a la deslegitimación de la discursividad tradicional de los partidos políticos más viejos, estos también se vieron expuestos a hablar en esos nuevos términos, aunque no entendieran o no quisieran usarlos.

Esta "tendencia", esta "fractura" y este "quiebre" dejan ver una significativa contradicción socio-discursiva y socio-económica (combinadas) que surge desde las modificaciones en el uso del lenguaje y sus códigos: usar una terminología que denota en buena medida la versión de un "culpable" que los mismos "acusados" (partidos tradicionales y élites políticoeconómicas) también usaron — pero sin poder

$16 \quad$ Ejemplo de estos refinamientos o ampliación de lenguaje se vio antes con la introducción de la terminología de pobreza, o con marginalidad en distintas etapas históricas, y según la presión de diferentes actores institucionales, nacionales o internacionales. Véase: Pérez Sáenz, 2014
La reflexión no busca la profundización en el manejo de los términos, sino del posicionamiento y legitimidad política al usarlos. De hecho, la discusión alrededor de la desigualdad y la exclusión fue baja; sin embargo, su nominación fue fundamental para ganar espacio y caudal de apoyo. A pesar de que esos mismos términos fueran contradictorios con los programas de gobiernos planteados desde los partidos políticos. culpar a fondo a otros ${ }^{18}$ _, es decir, "el rico antes recriminó al pobre que era pobre por la culpa del mismo pobre", con los nuevos códigos ya no se puede usar esa construcción discursiva en todo su potencial liberal; ahora "el pobre puede acusar al rico de que es rico porque se 'aprovecha del pobre', y el rico no puede acusar al pobre de casi nada", lo más que puede hacer es "acusar a otro rico" (y eso fue lo que se intentó por medio de ciertas referencias ambiguas), pero no fue del todo fuerte en la persuasión de campaña.

Esto se dio porque los anteriores códigos están tan desacreditados que son casi profanos. En alguna medida es lo que George Orwell llamó "mentalidad persecutoria"19, en donde se recupera la figura de chivo expiatorio como canalización de las "masas" y que recientemente se observa su aplicación durante la crisis económica mundial ${ }^{20}$, lo cual demuestra ser

18 Las versiones de desigualdad y exclusión hacen énfasis en los formatos estructurales, en lugar de la vertiente individual del "culpable". Sin embargo, la canalización comunicativa de los discursos demostró el elemento culpabilizador. No es inexistencia de responsables, sino que la versión discursiva señala a un único responsable, una moralización discursiva de la desigualdad y de la exclusión.

19 En el libro 1984, George Orwell destaca el argumento de la existencia de esa "mentalidad persecutoria" con la que se renueva la lucha política y repostula los tintes de maldad que fomenta la moralización en la política. Otras posibles formas para nombrar el fenómeno ver: Sabater (1998), quien también le llama a esto "conciencia fiscal" o "mentalidad acusatoria".

20 Un ejemplo de este uso lo rescató el economista Paul Krugman (2014), quien estudió los argumentos de la derecha estadounidense y señaló que la culpa del descalabro económico ocurrido en el 2008, fue del Congreso de los Estados Unidos (EE.UU) y no de la Banca Privada. En dicha reflexión contrapone esta versión de culpa del Congreso de los EE.UU. con lo que se podría llamar una contra-culpa en la dupla: líderes políticos y "especialistas" económicos. Krugman amortigua la idea de culpa con responsabilidades, lo cual muestra dos puntos importantes que se conectan con este documento: 1. la importancia de la política sobre la economía en términos de rescate financiero y económico; $y$ más importante aún 2. el marco contextual de la economía para catapultar un partido o candidato sobre otro. Esto hablando en términos de momento económico de un país, del cual aprovecharse para la generación de culpables "nacionales". Esta idea podría desarrollarse en otros documentos discursivos y políticos. 
un recurso potente para encausar una campaña política, sea electoral o de otro tipo; en este caso combinado con reconstrucciones de códigos en el marco del lenguaje. Esto llevó a la elaboración de campañas que incurrieron en incoherencias $y$ en postulados insípidos desde el caso de las élites políticas. Por otro lado, se construyeron campañas con un lenguaje aparentemente crítico, pero que estaban sobrecargadas de tradicionalidad mítica y de culpabilización.

Si bien, la idea de responsables no es descartable política y socialmente, lo que se postula es lo eficiente que es el factor culpabilizador durante la campaña del 2013-2014, que en años pasados se vino desarrollando y fue hasta inicio de los primeros años del siglo xxi que la figura del culpable forma parte de la elocución político-discursiva. Esto a su vez está fomentando una idea de "neutralidad responsable" sobre otros competidores políticos, mucho más manejable en los caudales electorales. No obstante, tienen que desenvolverse dentro de los mitos de la culturalidad costarricense para dar sentido - más allá de una cuestionada afiliación política- de lógicas y moralidades ejercidas en la política formal por medio del voto.

\section{BIBLIOGRAFÍA}

\section{LIBROS}

Ansolabehere, Se Iyenger, S. (1995). Going Negative. How political advertisements shrink land polarize the electorate. New York: The Free Press.

Caro, A. (1994). La publicidad que vivimos. España: Eresma \& Celeste Ediciones.

Castells, M. (1999). La sociedad red. La era de la información: economía, sociedad y cultura. México: Siglo Veintiuno Editores.

Del Rey Morató, J. (1989). La comunicación política. El mito de las izquierdas y las derechas. Madrid: eudema Universidad/ Manuales.

Eliade, M. (2013). El mito del eterno retorno. España: Editorial Alianza.

Fabbrini, S. (2009). El ascenso del príncipe democrático. Quien gobierna y cómo se gobiernan las democracias. Argentina: Fondo de Cultura Económica.

Fairclough, N. y Wodak, R. (2000). Análisis crítico del discurso. En Teum A. van Dijk (comp.). El discurso como interacción social. Estudios sobre el discurso II. Una introducción multidisciplinaria. Barcelona: Editorial Gedisa.

Figueroa, C. (2010). ¿En el umbral del posneoliberalismo? Izquierda y gobierno en América Latina. Guatemala: Editores F\&G.

Krugman, p.(2014). ¡Acabad ya con esta crisis!. Barcelona: Editorial CRITICA. Booket.

Liphart, A. (1999). La democracias contemporáneas. España: Ariel Ciencia Política.

Lozano, J.C. (1997). Teoría e investigación de la comunicación de masas. México, México D.F: Editorial Alhambra Mexicana.

Maravall, J.M. (2009). La confrontación política. España, Madrid: Editorial Taurus.

Molina, I. y Palmer, S. (2012). Historia de Costa Rica. San José, Costa Rica: Editorial de la Universidad de Costa Rica.

Pérez Sáinz, J.P. (2014). Mercados y bárbaros. La persistencia de las desigualdades de excedente en América Latina. Costa Rica: Federación Latinoamericana de Ciencias Sociales.

Raventós, C; Fournier, M; Ramírez; O; Gutiérrez, A; y García; R. (2005). Abstencionista en Costa Rica. ¿Quiénes son y por qué no votan?. San José, Costa Rica: Instituto de Investigaciones Sociales/Tribunal Supremo de Elecciones/ Instituto Interamericano de Derechos Humanos/Centro de Asesoría y Promoción Electoral.

Rodríguez, F. (2013). Costa Rica: ¿Quién decide? Elecciones, compañas y sociedad 1994.2010. Costa Rica: Federación Latinoamericana de Ciencias Sociales.

Rojas, M; y Castro, M. (2009). Elecciones 2006 y Referéndum: perspectivas diversas. San José, Costa Rica: Federación Latinoamericana de Ciencias Sociales.

Sabater, F. (1998). Las razones antimiliatares y otras razones. España, Barcelona: Editorial Compactos \& Anagrama. 
Sartori, G. (2013). Homo videns. La sociedad teledirigida. Colombia: Editorial Punto de lectura.

Sojo, C. (2010). Igualiticos. La construcción social de la desigualdad en Costa Rica. San José, Costa Rica: Federación Latinoamericana de Ciencias Sociales y Programa de las Naciones Unidas para el Desarrollo.

Van Dijk, T. (2003). El estudio del discurso. En: Van Dijk, Teun A. (comp.) El discurso como interacción social. Estudios sobre el discurso I. Una introducción multidisciplinaria. España, Barcelona: Gedisa Editorial.

\section{PUBLICACIONES PERIÓDICAS}

Agüero, M. (19 de febrero de 2014). Tributación pide a Johnny Araya información sobre clientes $y$ proveedores de sus sociedades. La Nación. Acceso el setiembre de 2015. http://www.nacion.com/nacional/politica/ Tributacion-Johnny-Araya-informacioncompras_0_1397660339.html

Akepsimidis, S. (10 de diciembre de 2013). Rodolfo Piza: un académico de cuna liberal y socialcristiana. La Nación. Acceso el setiembre de 2015. http://www. nacion.com/nacional/elecciones-2014/ Rodolfo-Piza-academico-liberalsocialcristiana_0_1383461659.html

Araya, A. (22 de enero de 2014). PLN cambia concentración de fuerza por 'domingo familiar' para cierre de campaña. $L a$ Nación. Acceso el setiembre de 2015. http://www.nacion.com/nacional/ PLN-concentracion-domingo-familiarcampana_0_1392060910.html

Calvo, L. (2 de febrero, 2014) Cuando los creían derrotados. Historias de otros. Acceso el setiembre de 2015. http://historiaslcr. blogspot.com/-2014/02/cuando-loscreian-derrotados.html?m=1

Carballo, P. (2013). Representaciones de y desde las élites Político-empresariales costarricenses. Estudio a partir de los medios de comunicación político-empresariales. Cuadernos de Ciencias Sociales de la Federación Latinoamericana de Ciencias Sociales, 161.
Carballo, p.(2015). Debatir o no debatir ¡He ahí la cuestión! Reflexión de la campaña electoral en Costa Rica 20132014. Revista de Ciencias Sociales, 147, 27-48.

Carrera, M. (2012). Los partidos importan. Democratización y evolución del sistema de partidos en América Latina. Revista Nueva Sociedad, 240.

Fernández, E. (24 de marzo de 2014). Partido Liberación Nacional recibe la mayor porción de la deuda política. El Financiero. Acceso el setiembre de 2015. http://www. elfinancierocr.com/economia-y-politica/ Partido-Liberacion-Nacional-porcionpolitica_0_487751229.html

Jiménez, G. (29 de octubre de 2013) Sobre izquierdas, comunismos, ideologías, confusiones y realidades: cosa de ubicarse. Cultura CR [en línea]. Acceso el setiembre de 2015. http://www. culturacr.net/13/10/Sobre-izquierdascomunismos-ideologias-confusiones$y$-realidades-cosa-de-ubicarse.html\#. VvhSHNLhDIU

López, N. (1 de febrero de 2014). Gran incertidumbre en Costa Rica ante las elecciones presidenciales. El Mundo. Acceso el setiembre de 2015. http://www. elmundo.es/internacional/2014/02/01/52eb935dca4741197f8b4577.html

Luis Guillermo Solís quiere acercar Costa Rica a Latinoamérica. (3 de abril de 2014). Teletica [en línea]. Acceso el setiembre de 2015. http://www.teletica. com/Noticias/49003-Luis-GuillermoSolis-quiere-acercar-Costa-Rica-aLatinoamerica.note.aspx)

Luis Guillermo Solís, la sorpresa de la primera vuelta electoral costarricense. (3 de marzo de 2014). Radio Francia Internacional. Acceso el setiembre de 2015. http://es.rfi.fr/americas/20140203luis-guillermo-solia-gran-sorpresa-de-laprimera-vuelta-electoral-costarricense

Mata, E. (25 de octubre de 2013). Otto Guevara propone vender Fanal y reacomodar gasto para frenar déficit fiscal. La Nación. Acceso el setiembre 
de 2015. http://www.nacion.com/ nacional/Otto-Guevara-Fanal-Recopereacomodar_0_1374262714.html

Mata, E. (27 de febrero de 2014). Johnny Araya gana simpatías con Alianza Evangélica Nacional. La Nación. Acceso el setiembre de 2015.: http://www.nacion. com/nacional/Johnny-Araya-AlianzaEvangelica-Nacional_0_1399260255.html

Murillo, A. (26 enero de 2014). Cristianismo, el nuevo giro en el discurso de Otto Guevara. La Nación. Acceso el setiembre de 2015. http://www. nacion.com/nacional/elecciones-2014/ Cristianismo-nuevo-giro-discursoGuevara_0_1392860783.html

Murillo, A. (27 de febrero de 2014). pac logra sosegar sus pugnas para buscar 'objetivo superior'. La Nación. Acceso el setiembre de 2015. http://www. nacion.com/nacional/elecciones-2014/ PAc - s o s e gar - pug na s - o b j e t i vo superior_0_1399260062.html

Oviedo, E. (27 de noviembre de 2013). Movimiento Libertario lideró gasto en publicidad en primer mes. La Nación. Acceso el setiembre de 2015. http://www. nacion.com/nacional/elecciones-2014/ Libertario-lidero-gasto-publicidadprimer_0_1380861902.html

Oviedo, E. (29 de marzo de 2014). Liberación Nacional busca donaciones para afrontar deudas de la campaña. La Nación. Acceso el setiembre de 2015. http://www. nacion.com/nacional/elecciones-2014/ PLN-donaciones-afrontar-deudascampana_0_1405259485.html

Oviedo, E. (5 de febrero de 2014). Movimiento Libertario queda con un enorme hueco en sus finanzas. La Nación. Acceso el setiembre de 2015. http://www. nacion.com/nacional/elecciones-2014/ Movimiento-Libertario-queda-enormefinanzas_0_1394860561.html

Rovira, J. (2007). Desafíos políticos de la Costa Rica actual. Editorial de la Universidad de Costa Rica.

Ruiz, G. (19 de agosto de 2013). Impugnan potestad de candidato del PLN, Johnny
Araya, para nombrar delegados súpernumerarios. La Nación. Acceso el setiembre de 2015. http://www.nacion. $\mathrm{com} / \mathrm{nacional} / \mathrm{politica/Elecciones-}$ 2014-PartidoLiberacion NacionalA samblea_Nacional-delegados_ supernumerarios_0_1360864143.html

Salom, R. (2005). Los procesos de corrupción y las perspectivas de la democracia en Costa Rica. Revista Nueva Sociedad, 196, pp-pp. Acceso el setiembre de 2015. www. nuso.org/upload/articulos/3248_1.pdf

Solano, H. (2 de abril de 2014). PAC denuncia falsas llamadas para desconvocar a sus colaboradores para elecciones del domingo. La Nación. Acceso el setiembre de 2015. http://www.nacion.com/ nacional/-elecciones2014/

Soto, J. (15 de enero de 2014). José María Villalta asegura que no es comunista. Costa Rica Hoy. Acceso el setiembre de 2015. http://www.crhoy.com/jose-mariavillalta-asegura-que-no-es-comunistaw317m1x/

Treminio, I. (Julio de 2010). Ensayo y error: la puesta en práctica de la democracia directa en Costa Rica. Revista Centroamericana de Ciencias Sociales, 8(1), 123-153.

Vargas, M. (10 de enero de 2014). Parodias son algo que marcan las campañas del Partido Acción Ciudadana. Teletica [en línea]. Acceso el setiembre de 2015. http://www.teletica.com/Noticias/38538Parodias-son-algo-que-marcanlas-campanas-del-Partido-AccionCiudadana.note.aspx

OTROS

Contraloría General de la República. (2014). Presupuestos públicos 2014. Situación $y$ perspectivas. Acceso el setiembre de 2015. www.cgr.cr/rev_dig/presup pub/2014/files/assets/downloads/ publicacion.pdf

Fecha de ingreso: $30 / 08 / 2015$ Fecha de aprobación: 18/05/2016 
